\title{
The vitamin D receptor and inducible nitric oxide synthase associated pathways in acquired resistance to Cooperia oncophora infection in cattle
}

\author{
Robert W Li, Congjun Li, Louis C Gasbarre
}

\begin{abstract}
Cooperia oncophora is an economically important gastrointestinal nematode in ruminants. Acquired resistance to Cooperia oncophora infection in cattle develops rapidly as a result of prior infections. Naïve cattle, when given a primary infection of high-dose infective L3 larvae, develop a strong immunity to subsequent reinfection. Compared to primary infection, reinfection resulted in a marked reduction in worm establishment. In order to understand molecular mechanisms underlying the development of acquired resistance, we characterized the transcriptomic responses of the bovine small intestine to a primary infection and reinfection. A total of 23 pathways were significantly impacted during infection. The vitamin D receptor activation was strongly induced only during reinfection, suggesting that this pathway may play an important role in the development of acquired resistance via its potential roles in immune regulation and intestinal mucosal integrity maintenance. The expression of inducible nitric oxide synthase (NOS2) was strongly induced during reinfection but not during primary infection. As a result, several canonical pathways associated with NOS2 were impacted. The genes involved in eicosanoid synthesis, including prostaglandin synthase 2 (PTGS2 or COX2), remained largely unchanged during infection. The rapid development of acquired resistance may help explain the lack of relative pathogenicity by Cooperia oncophora infection in cattle. Our findings facilitate the understanding of molecular mechanisms underlying the development of acquired resistance, which could have an important implication in vaccine design.
\end{abstract}

\section{Introduction}

Cooperia oncophora is one of the most economically important gastrointestinal nematodes in ruminants that result in production inefficiency. In Brazil, over $70 \%$ of parasites recovered from cattle grazed on pasture belong to the genus Cooperia [1]. While clinical symptoms are generally absent or relatively mild, C. oncophora infection has been shown to reduce live weight gain as much as $13.5 \%$ of total cattle bodyweights [2], possibly due to inappetence and nutritional deficiency. Pathophysiological changes induced by infection are typically restricted to the site of infection, mainly in the duodenum and jejunum. These changes include morphological and structural alterations in intestinal villi $[2,3]$, loss of plasma protein into the gut [3] and enhanced mucus excretion [3,4].

\footnotetext{
* Correspondence: robert.li@ars.usda.gov

Animal and Natural Resources Institute, United States Department of Agriculture, Agricultural Research Service, Beltsville, MD 20705, USA
}

C. oncophora infection in cattle elicits a Th2-like immune response, characterized by up-regulation of IL-4 and the involvement of both eosinophils and mucosal IgA [4-7]. Host serological response to C. oncophora infection has been extensively studied [6,8-10]. C. oncophora-specific serum and mucosal IgG1 and IgA are strongly induced upon experimental challenge in cattle [8]. Moreover, the levels of Cooperia-specific IgA are significantly higher in intermediate responders than in low responders in cattle [9] and expulsion of the adult Cooperia worm appeared to be associated with a significant increase in mucosal IgA and an influx of eosinophils [6]. PIGR, a gene responsible for trans-epithelial transport of polymeric immunoglobulins, such as IgA dimers and IgM pentamers, into mucosal and glandular secretions, is strongly up-regulated in the heifers resistant to parasitic nematodes after experimental parasite challenge [7]. The peak in antibody titres is preceded by a significant increase in $\mathrm{B}$ and $\mathrm{MHCII}^{+}$cells in the draining lymph nodes, suggesting that B cells may play an 
important role in development of acquired immunity against the parasite [8].

In ruminants, adult animals often exhibit acquired resistance to gastrointestinal nematodes. This process tends to display a temporal characteristic. The ability to reject incoming larvae is first acquired, followed by depressing female fecundity and then by expelling adult worms by the host. The prevention of worm establishment in the host tissue, which is determined by host age, seems most important and requires a threshold worm burden in order to invoke a strong immune response [11]. Compared to the abomasal nematode Ostertagia ostertagi, which requires a prolonged exposure before acquired resistance becomes effective [12,13], protective immunity to reinfection in cattle develops rapidly following a primary C. oncophora infection. A significant reduction in worm burdens can be achieved in primed cattle with a primary infection [14]. In these animals, acquired resistance is also manifested by increased percentage of L4 larvae. In addition, worm length and fecundity are also significantly reduced. This observed immunity is also confirmed in cattle during natural infection. Calves moderately exposed to $C$. oncophora during the first grazing season are absent of any C. oncophora larvae in their fecal cultures during the second grazing season $[15,16]$. Accumulated evidence suggests that a rapid development of protective immunity may well explain relatively mild clinical symptoms and lack of severe pathogenicity observed in cattle exposed to C. oncophora infections. While the effect of host response types or genetic factors on worm establishment and infection doses on worm morphology and reproduction are well understood, molecular mechanisms underlying the development of acquired resistance in cattle have not received any attention. In this study, we aim to understand the underlying mechanisms that contribute to the development of acquired resistance against $C$. oncophora infection in cattle, which should have a positive impact on formulating optimal drug-independent nematode control strategies.

\section{Materials and methods}

\section{Animals and worm burdens}

Sixteen Holstein bull calves were purchased locally within $48 \mathrm{~h}$ after birth. The animals were fed ad libitum with a standard calf ration and maintained on concrete for the duration of the experiment. These animals were randomly divided into 4 groups (naïve control, primary infection, drug-treated control, reinfection) with 4 animals in each group. After reaching $\sim 4$ months of age, twelve of these 16 nematode-naïve animals were orally infected with a single dose of $C$. oncophora infective L3 larvae $\left(10^{5}\right.$ larvae per animal) for 14 days post infection (dpi). The L3 larvae were obtained from cultures maintained at the USDAARS Beltsville facilities. Four uninfected naïve animals were used as controls. Four out of the 12 infected animals (primary infection) at 14 dpi and four naïve control animals were sacrificed. The remaining 8 infected calves were treated with a $2 \times$ labeled dose of fenbendazole (SafeGuard) to remove existing parasites. These calves were allowed to rest for 30 days on concrete. Four of the 8 drug-treated calves were then infected with a single dose of $10^{5} \mathrm{~L} 3$ larvae per animal for 14 days (reinfection) and the remaining four drug-treated calves remained uninfected and served as drug-treated controls. Small intestine tissues were collected from the jejunum approximately three meters from the pyloric sphincter and snap frozen in liquid nitrogen prior to storage at $-80^{\circ} \mathrm{C}$ until total RNA was extracted. The animal maintenance and handling were based on the protocol approved by The USDA-ARS Animal Care and Use Committee; and Institutional Animal Care and Use Committees guidelines were strictly followed. Fecal egg count (egg per gram of feces or EPG) was monitored during the repeat infection experiment using zinc sulfate double centrifugation and parasite burdens were determined as previously described [13].

\section{RNA Extraction, real-time RT-PCR, and microarray analysis}

Total RNA extraction, real-time RT-PCR and microarray fabrication and hybridization were performed as previously described $[7,17]$. Briefly, total RNA was extracted using Trizol (Invitrogen, Carlsbad, CA, USA) and further purified using an RNeasy Mini kit (Qiagen, Valenica, CA, USA). RNA integrity was verified using a Bioanalyzer 2100 (Agilent, Palo Alto, CA, USA). For real-time RTPCR, the cDNA synthesis was performed with an iScript cDNA Synthesis kit (Bio-Rad, Hercules, CA, USA). Realtime RT-PCR analysis was carried out with the iQ SYBR Green Supermix kit (Biorad) using $200 \mathrm{nM}$ of each amplification primer and the $1^{\text {st }}$-strand cDNA (100 ng of the input total RNA equivalents) in a $25 \mu \mathrm{L}$ reaction volume as described [7]. The amplification was carried out on an iCycler iQ ${ }^{\mathrm{TM}}$ Real Time PCR Detection System (BioRad) with the following profile: $95^{\circ} \mathrm{C}-60 \mathrm{~s} ; 40$ cycles of $94^{\circ} \mathrm{C}-15 \mathrm{~s}, 60^{\circ} \mathrm{C}-30 \mathrm{~s}$, and $72^{\circ} \mathrm{C}-30 \mathrm{~s}$. A melting curve analysis was performed for each primer pair. The ribosomal protein S29 (RPS29), with relatively constant expression levels across all experiment samples, was used as an endogenous control. Relative gene expression data was calculated using the $2^{-\Delta \Delta C T}$ method [18]. The fold change was normalized against the naive group.

The bovine microarray, which included 86191 unique 60 mer oligonucleotides synthesized in situ, each repeated 4 times on the microarray, representing 45383 bovine genes and/or expressed sequence tags (ESTs), was previously described [17]. After hybridization, scanning and image acquisition, data were extracted from raw images using NimbleScan software (Roche, Indianapolis, IN, USA). A total of 16 microarrays, 4 biological replicates 
per treatment group, were used in this experiment (GEO accession\# GSE24402). Relative signal intensities ( $\log 2)$ for each feature were generated using the robust multiarray average algorithm [19]. The data were then processed based on the quantile normalization method [20]. The background-adjusted, normalized, and logtransformed intensity values were further analyzed using MeV v4.2. [21]. Significantly regulated genes were identified using the method suggested by Guo et al. [22] based on their significance $(P<0.05)$ and followed by fold change (2 fold as a cutoff). A nucleotide BLAST was conducted against the Reference mRNA Sequences Database (RefSeq) for all sequences that were significantly impacted during infection using 60mer oligo sequences on the microarray (cutoff E Value $<10^{-8}$ ). These genes are listed in Additional file 1. After removing redundancy in which a gene was represented by multiple sequences, genes with annotation and approved gene symbols (Table 1) were used for pathway analysis discussed below.

Genes significantly regulated during infection were analyzed using Ingenuity Pathways Analysis (IPA) software v8.7 (Ingenuity Systems, Redwood City, CA, USA) as described previously [13,23]. Genes significantly upregulated and down-regulated were analyzed separately. Genes with known gene identifiers (gene symbols) and their corresponding expression values were uploaded into the software. Canonical pathways were identified based on two parameters: (1) A ratio of the number of genes from the data set that map to the pathway divided by the total number of genes that map to the canonical pathway, and (2) a P value calculated using Fischer's exact test, which determines the probability that the association between the genes in the data set and the canonical pathway is due to chance alone.

\section{Western blot analysis}

Western blot analysis was essentially the same as described [13]. Briefly, crude proteins were extracted from bovine small intestine samples using Mammalian Protein Extraction Reagent (Pierce, Rockford, IL, USA) with a protease inhibitor cocktail (Sigma, St. Louis, MO, USA) added prior to use. After homogenization, the samples were briefly centrifuged at $4^{\circ} \mathrm{C}$ for $2 \mathrm{~min}$ at $10000 \times g$ to remove debris. Crude protein was quantified using a modified Branford method and Western blot analysis performed as described [4]. Briefly, the protein from different samples was separated by SDS PAGE on 2 identical 4 to $20 \%$ polyacrylamide gradient gels. One gel was stained with Simply Blue Safestain (Invitrogen) and served as loading control. Another gel was used for Western blot and imaging analysis. The Western blot was probed with the following primary antibodies, SPP1 (OPN) mouse monoclonal antibody (sc-21742, Santa Cruz Biotechnology, Santa Cruz, CA,
USA) and GCNT3 goat polyclonal antibody (ab77728, Abcam, Cambridge, MA, USA). After washing, these blots were incubated with an IRdye labeled secondary antibody (Li-Cor Bioscience, Lincoln, NE, USA). The bands were detected using a Li-Cor Odyssey Infrared Imaging System (Li-Cor). The relative density of the target bands on the blots was quantified using the imaging software UN-SCAN-IT (Silk Scientific, Orem, UT, USA).

\section{Results}

\section{Parasitology and worm counts}

The naïve control calves remained worm-free during the experiment. No worms were recovered from drug-treated control animals, suggesting that a $2 \times$ labeled dose of fenbendazole (Safe-Guard) is sufficient to eliminate existing parasites. EPG was monitored weekly during the rest period. A low EPG value (EPG = 8) was detected only in one of the animals in a single time point, providing further evidence the efficacy of drug drenching. Approximately a $56 \%$ reduction in worm burden was observed in reinfected calves (mean worm counts \pm SD $=10334 \pm 3$ 585) compared to the animals with only a primary infection (23 $883 \pm 7833)$ at $14 \mathrm{dpi})$. The difference is marginally significant $(P<0.1)$, probably due to a substantial variation in worm burden in an out-bred population used in this challenge experiment. While uncharacterized genetic makeup of experiment animals and a small sample size used in challenge studies are a major concern, a significant reduction in worm burden and a higher percentage of immature larvae recovered in reinfected animals (15.2\% vs. $9.4 \%$ in primarily infected animals, $P<0.1)$ suggested these animals had indeed acquired protective immunity to infection.

\section{Transcriptomic profiles and pathway analysis}

Transcriptomic disruptions in the bovine jejunum induced by $C$. oncophora between a primary infection and a drug-attenuated reinfection were compared using a bovine high-density microarray consisting of 86191 unique 60mer oligonucleotides. Based on both significance derived from an unpaired $t$-test $(P \leq 0.05)$ and fold change, a total of 308 unique sequences were impacted during infection. The alteration in the bovine transcriptome by the parasite infection appeared to be minimal; and only a small fraction of the transcriptome ( $<1 \%)$ was affected. Among the 308 sequences induced, eighty unique genes that were significantly up-regulated can be identified with annotation (Table 1).

Approximately forty genes were significantly up-regulated during the primary infection only (Table 1 ). These genes include basic leucine zipper and W2 domains 1 and 2 (BZW1 and BZW2), dendrin (DDN), glucosaminyl (N-acetyl) transferase 3, mucin type (GCNT3), hepatocyte growth factor (HGF), major histocompatibility 
Table 1 Genes significantly induced in the bovine small intestine by Cooperia oncophora infections*

\begin{tabular}{|c|c|c|c|c|}
\hline Bovine RefSeq_ID & Symbol & Description & Primary infection & Reinfection \\
\hline XM_587930.4 & $\mathrm{ABCG} 1$ & similar to ATP-binding cassette sub-family G member 1 & $2.29^{*}$ & 1.08 \\
\hline NM_174501.2 & ALOX15 & arachidonate 15-lipoxygenase & 1.27 & $2.42^{*}$ \\
\hline NM_001083508.1 & BAALC & brain and acute leukemia, cytoplasmic & 0.51 & $2.07^{*}$ \\
\hline XM_587691.3 & BEST4 & similar to bestrophin 4 & 0.74 & $2.05^{*}$ \\
\hline XM_876130.3 & BZW1 & basic leucine zipper and W2 domains 1 & $2.78^{*}$ & 1.33 \\
\hline NM_001104961.1 & BZW2 & basic leucine zipper and W2 domains 2 & $3.89^{*}$ & 0.66 \\
\hline NM_001076195.1 & CALB1 & calbindin 1, $28 \mathrm{kDa}$ & 1.15 & $2.13^{*}$ \\
\hline NM_001017934.2 & ССТ3 & chaperonin containing TCP1, subunit 3 (gamma) & $2.06^{*}$ & 0.52 \\
\hline XM_869285.3 & $\mathrm{CDH} 26$ & similar to cadherin-like 26 & $39.48^{* * *}$ & $13.08^{*}$ \\
\hline XM_583707.4 & CDK8 & similar to MGC81962 protein & $2.55^{*}$ & 1.26 \\
\hline NM_176788.1 & CEBPB & CCAAT/enhancer binding protein (C/EBP), beta & 1.15 & $2.09^{*}$ \\
\hline XM_001790249.1 & CKAP5 & similar to colonic and hepatic tumor over-expressed protein & $2.20^{*}$ & 0.81 \\
\hline NM_001101980.1 & COL17A1 & collagen, type XVII, alpha 1 & 0.76 & $2.06^{*}$ \\
\hline NM_001034340.1 & CYR61 & cysteine-rich, angiogenic inducer, 61 & 0.87 & $2.62^{* *}$ \\
\hline NM_001102301.1 & DDN & dendrin & $2.35^{*}$ & 0.97 \\
\hline NM_001046036.1 & DIMT1L & DIM1 dimethyladenosine transferase 1 -like (S. cerevisiae) & $2.77^{*}$ & 1.23 \\
\hline NM_001010992.3 & $\mathrm{DlO} 2$ & deiodinase, iodothyronine, type & $4.38^{*}$ & $2.41^{*}$ \\
\hline NM_001046052.1 & DYNC1LI1 & dynein, cytoplasmic 1, light intermediate chain 1 & $2.09^{*}$ & 0.74 \\
\hline NM_001143864.1 & ELP2 & elongation protein 2 homolog (S. cerevisiae) & $3.82^{* *}$ & 1.11 \\
\hline NM_001102519.1 & ENDOD1 & endonuclease domain containing 1 & 1.45 & $2.49^{*}$ \\
\hline XM_614853.4 & ETV5 & similar to ets variant gene 5 (ets-related molecule) & 2.53 & $2.32^{*}$ \\
\hline NM_001008665.1 & F11 & coagulation factor $\mathrm{XI}$ & 1.01 & $2.01^{*}$ \\
\hline NM_174541.2 & GABRA2 & gamma-aminobutyric acid (GABA) A receptor, alpha 2 & 1.57 & $2.34^{* *}$ \\
\hline NM_001075844.1 & GABRA5 & gamma-aminobutyric acid (GABA) A receptor, alpha 5 & 2.34 & $0.49^{* *}$ \\
\hline NM_001038143.1 & GCLM & glutamate-cysteine ligase, modifier subunit & 1.22 & $2.50^{* *}$ \\
\hline NM_205809.1 & GCNT3 & glucosaminyl ( $\mathrm{N}$-acetyl) transferase 3 , mucin type & $7.66^{* *}$ & 2.47 \\
\hline XM_868229.3 & GIF & similar to gastric intrinsic factor (vitamin B synthesis) & 0.80 & $3.69^{* *}$ \\
\hline XM_865266.3 & GPR120 & similar to $\mathrm{G}$ protein-coupled receptor 120 & $2.02^{*}$ & 1.25 \\
\hline NM_001080354.1 & GSTM4 & glutathione S-transferase mu 4 & $2.81^{*}$ & 1.61 \\
\hline XM_605913.4 & HERC6 & similar to hect domain and RLD 6 & 0.74 & $2.62^{*}$ \\
\hline NM_001031751.1 & HGF & hepatocyte growth factor & $2.05^{*}$ & 1.43 \\
\hline NM_001105651.1 & HLA-A & major histocompatibility complex, class I, A & $2.02^{*}$ & 0.43 \\
\hline XM_001253142.1 & KSR2 & similar to Kinase suppressor of Ras 2 & 2.10 & $0.50^{*}$ \\
\hline NM_001076122.1 & HS3ST1 & heparan sulfate (glucosamine) 3-O-sulfotransferase 1 & 1.22 & $2.00^{* *}$ \\
\hline NM_001040563.1 & HTATIP2 & HIV-1 Tat interactive protein 2, $30 \mathrm{kDa}$ & $2.07^{*}$ & 1.15 \\
\hline NM_174644.2 & $\mathrm{IDH} 3 \mathrm{~A}$ & isocitrate dehydrogenase $3(\mathrm{NAD}+)$ alpha & $2.27^{*}$ & 1.24 \\
\hline NM_001075588.1 & $|F| 6$ & interferon, alpha-inducible protein 6 & 0.17 & $2.55^{*}$ \\
\hline NM_001046210.1 & IL1R2 & interleukin 1 receptor, type ॥ & 1.03 & $2.06^{*}$ \\
\hline XM_590057.4 & KIAA0415 & hypothetical protein LOC512522 & 1.30 & $2.45^{*}$ \\
\hline NM_001046411.1 & KRT7 & keratin 7 & $2.30^{*}$ & 1.87 \\
\hline XM_595458.4 & LIPM & similar to Lipase member M precursor & 1.57 & $2.21^{*}$ \\
\hline XM_001249810.2 & LONRF3 & similar to LON peptidase N-terminal domain and RING finger protein 3 & 0.97 & $2.06^{*}$ \\
\hline NM_173933.2 & LPO & lactoperoxidase & 2.33 & $0.16^{* *}$ \\
\hline NM_001097565.1 & LRP8 & low density lipoprotein receptor-related protein 8 & $2.57^{*}$ & 1.79 \\
\hline XM_001789987.1 & METTL8 & methyltransferase like 8 & 0.87 & $2.20^{*}$ \\
\hline NM_173940.2 & MX1 & myxovirus (influenza virus) resistance 1 & 0.54 & $2.05^{*}$ \\
\hline XM_613028.3 & NEB & nebulin & $1.82^{* *}$ & $2.25^{*}$ \\
\hline NM_001076799.1 & NOS2 & nitric oxide synthase 2 , inducible & 0.97 & $2.18^{* *}$ \\
\hline XM_592814.2 & $\mathrm{P} 2 \mathrm{RX} 1$ & similar to P2X purinoceptor 1 (ATP receptor) & $3.14^{*}$ & 1.19 \\
\hline NM_001001600.1 & PGA5 & pepsinogen 5, group I (pepsinogen A) & 1.21 & $2.20^{*}$ \\
\hline
\end{tabular}


Table 1 Genes significantly induced in the bovine small intestine by Cooperia oncophora infections* (Continued)

\begin{tabular}{|c|c|c|c|c|}
\hline XM_583514.4 & PGM2 & phosphoglucomutase 2 & $2.89^{*}$ & 0.70 \\
\hline NM_001035017.1 & PHGDH & phosphoglycerate dehydrogenase & $2.62^{*}$ & 1.09 \\
\hline XM_601308.3 & POLS & similar to DNA polymerase sigma & 1.01 & $2.06^{* *}$ \\
\hline NM_174432.2 & PRDX3 & peroxiredoxin 3 (PRDX3) & $2.16^{*}$ & 0.51 \\
\hline NM_174690.1 & PRSS2 & protease, serine, 2 (trypsin 2) & $3.44^{*}$ & 1.13 \\
\hline NM_001105323.1 & PTGS1 & prostaglandin-endoperoxide synthase 1 & $2.39^{*}$ & 1.52 \\
\hline NM_001103316.1 & PTPLAD1 & protein tyrosine phosphatase-like A domain containing 1 & 1.45 & $2.40^{*}$ \\
\hline NM_001046303.1 & RELL2 & RELT-like 2 & 2.07 & $0.27^{* *}$ \\
\hline NM_001080232.1 & RGS13 & regulator of G-protein signaling 13 & 1.26 & $2.63^{*}$ \\
\hline NM_001045941.1 & RSAD2 & radical S-adenosyl methionine domain containing 2 & 0.40 & $3.18^{*}$ \\
\hline NM_173959.4 & SCD & stearoyl-CoA desaturase (delta-9-desaturase) & $2.21^{*}$ & 0.95 \\
\hline XM_590757.3 & SEMA3B & Sema domain, short basic domain, secreted,3B & 0.77 & $2.03^{*}$ \\
\hline NM_001099211.1 & $\mathrm{SF} 3 \mathrm{~A} 2$ & splicing factor 3a, subunit 2, $66 \mathrm{kDa}$ & 1.03 & $2.12^{*}$ \\
\hline NM_001099378.1 & SLC15A1 & solute carrier family 15 (oligopeptide transporter), member 1 & $2.19^{*}$ & 0.57 \\
\hline XM_867835.3 & SLC22A15 & similar to solute carrier family 22, member 15 & 1.58 & $2.57^{*}$ \\
\hline NM_176640.2 & SLC35A2 & solute carrier family 35 (UDP-galactose transporter), member A2 & $2.07^{*}$ & 1.30 \\
\hline XM_001790621.1 & SLC38A1 & solute carrier family 38 , member 1 & $2.50^{*}$ & $1.70^{*}$ \\
\hline NM_001101994.1 & SLC6A12 & solute carrier family 6 , member 12 & 2.08 & $0.32^{*}$ \\
\hline NM_174187.2 & SPP1 & secreted phosphoprotein 1 & 1.01 & $4.69^{*}$ \\
\hline NM_001046456.1 & TICAM2 & toll-like receptor adaptor molecule 2 & $3.29^{*}$ & 1.04 \\
\hline NM_001035107.1 & TINAG & tubulointerstitial nephritis antigen & 1.69 & $3.41^{*}$ \\
\hline NM_001076856.1 & TMEM66 & transmembrane protein 66 & $2.99^{*}$ & 1.03 \\
\hline XM_600015.4 & TNFSF9 & similar to tumor necrosis factor (ligand) superfamily, member 9 & $2.61^{* *}$ & 1.02 \\
\hline NM_001038155.1 & TNS4 & tensin 4 & $2.84^{*}$ & 1.88 \\
\hline NM_001012284.1 & UBA7 & ubiquitin-like modifier activating enzyme 7 & 0.38 & $2.37^{*}$ \\
\hline NM_001103233.1 & ULBP3 & UL16 binding protein 3 & $2.23^{*}$ & 0.31 \\
\hline NM_001035075.1 & XAF1 & XIAP associated factor 1 & 0.55 & $2.20^{* *}$ \\
\hline NM_001102354.1 & $\mathrm{XRCC2}$ & X-ray repair complementing defective repair in Chinese hamster cells 2 & 1.40 & $2.36^{* *}$ \\
\hline XM_585095.4 & ZBP1 & similar to Z-DNA binding protein 1 & 0.44 & $2.20^{* *}$ \\
\hline XM_874604.3 & ZNF71 & similar to zinc finger protein 71 & $2.98^{*}$ & 1.14 \\
\hline
\end{tabular}

*Only sequences with annotation are listed.

complex, class I, A (HLA-A), toll-like receptor adaptor molecule 2 (TICAM2), and UL16 binding protein 3 (ULBP3). On the other hand, at least 44 genes, such as calbindin 1 (CALB1), collagen, type XVII, alpha 1 (COL17A1), interferon, alpha-inducible protein 6 (IFI6), interleukin 1 receptor, type II (IL1R2), nitric oxide synthase 2, inducible (NOS2), and secreted phosphoprotein 1 (SPP1, osteopontin), were significantly induced only during reinfection. Several genes, such as cadherinlike molecule 26 (CDH26), nebulin (NEB), deiodinase, iodothyronine, type II (DIO2), and solute carrier family 38, member 1 (SLC38A1), were significantly up-regulated during both the primary infection and reinfection. Genes significantly repressed during infection, such as adrenergic, alpha-1B-, receptor (ADRA1B), cytochrome P450, family 4, subfamily A, polypeptide 11 (CYP4A11), and hypoxia inducible factor 3 , alpha subunit (HIF3A), were listed in Additional file 1.
Twenty three pathways were significantly impacted $(P<$ 0.05) during infection (Additional file 2). Eight pathways in which their genes were down-regulated during primary infection included fatty acid metabolism, lysine degradation, fatty acid elongation in mitochondria, and LPS/IL-1 mediated inhibition of RXR function. During reinfection, three pathways whose genes were down-regulated, such as calcium signaling and fatty acid metabolism, were significantly impacted. Fatty acid metabolism was seemingly the only pathway suppressed during both primary infection and reinfection. Twelve pathways were significantly stimulated during infections as evidenced by up-regulation of the genes involved in these pathways. LXR/RXR activation was the only pathway stimulated during both primary infection and reinfection while the VDR/RXR activation pathway was stimulated only during reinfection (Figure 1). Notably, NOS2 was involved in 5 out the 8 pathways impacted during reinfection. The eicosanoid pathway, 


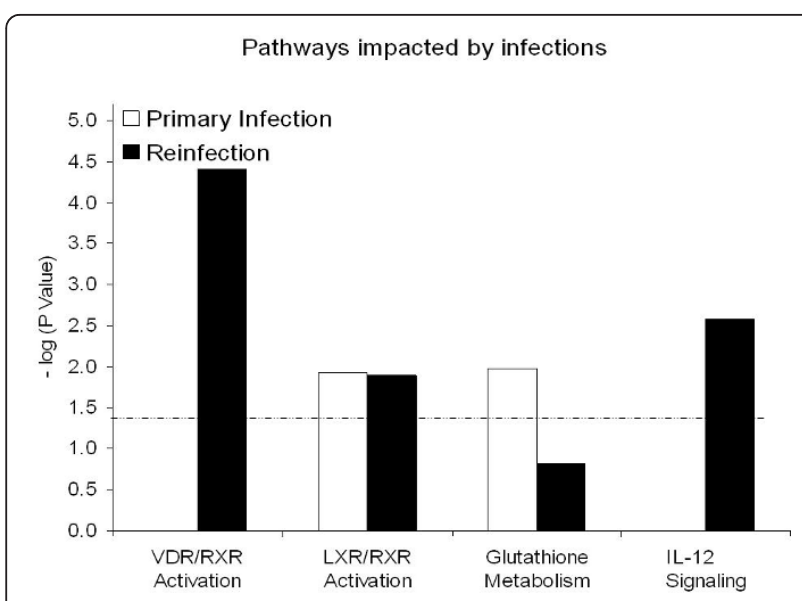

Figure 1 Selected pathways significantly impacted in the bovine small intestine during Cooperia oncophora infection at $14 \mathbf{d p i}$. The dashed line represents a significance level at $P<0.05$. $N=4$

which is significantly impacted only at 28 dpi during C. oncophora primary infection in cattle [7], was not seemingly involved in the development of acquired resistance.

\section{Quantitative PCR and Western blot analysis}

The mRNA expression of 16 genes was analyzed using real-time RT-PCR (Additional file 3), which were selected on the basis of their presumed biological relevance. These include 10 genes in the eicosanoid pathway such as 5-lipoxygenase activating protein (ALOX5AP or FLAP), prostaglandin synthase 2 (PTGS2 or COX2), leukotriene A4 hydrolase (LTA4H), leukotriene C4 synthase (LTC4), and thromboxane A synthase (TBXAS1). While arachidonate 15-lipoxygenase (ALOX15) was slightly upregulated during reinfection, consistent with the results obtained using the oligo microarray, other genes, including COX2 (Figure 2), remained largely unchanged. Quantitative PCR also confirmed up-regulation of NOS2 at the mRNA level during reinfection (Figure 2). This gene was significantly up-regulated at $14 \mathrm{dpi}$ based on quantitative PCR analysis, which is in agreement with the microarray results. CDH26 expression was induced to a much greater extent during primary infection than during reinfection, 82 vs. 21 fold (Figure 3), compared to their respective controls. The vitamin D3 receptor (VDR) expression was slightly elevated during both primary infection and reinfection $(\approx 1.7$ fold) compared to its respective controls. The mRNA level of mucin $5 \mathrm{~B}$ (MUC5b) in the small intestine was very low and unchanged during infection. However, MUC2 expression was up-regulated during primary infection but not during reinfection. Interestingly, GCNT3 mRNA followed the same pattern as MUC2, which were strongly upregulated only during primary infection, compared to

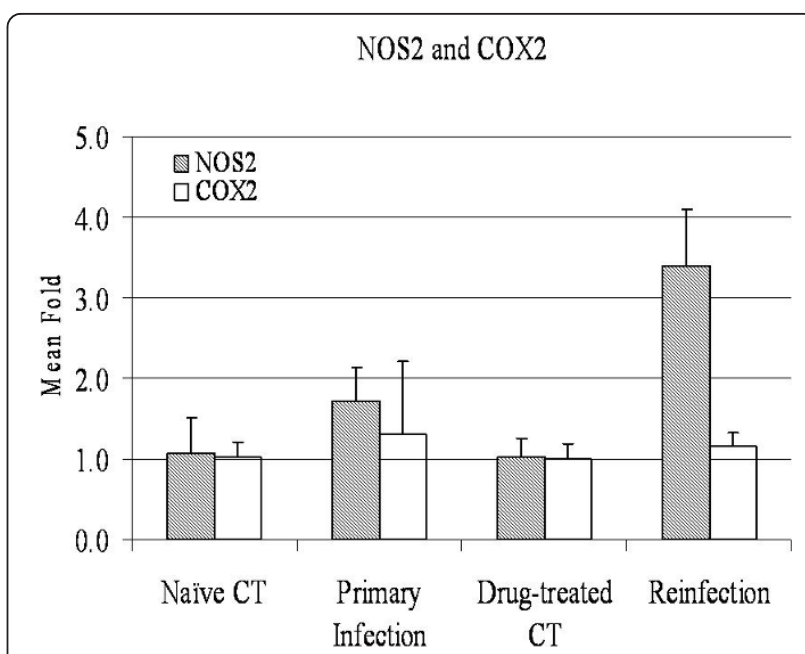

Figure 2 The expression profiles of NOS2 and COX2 in the bovine small intestine during Cooperia oncophora infection at $14 \mathrm{dpi}$. The expression value at the mRNA level was detected using quantitative RT-PCR. The expression value of the naive control group was set as 1.0. The fold change $(N=4)$ were calculated using the $2^{-\triangle \Delta C T}$ method and normalized against the naive control group (mean $\pm \mathrm{SD})$. NOS 2 = nitric oxide synthase 2 , inducible; COX2 = PTGS2 (prostaglandin-endoperoxide synthase 2 (prostaglandin G/H synthase and cyclooxygenase)).

naïve controls. The relative amount of both MUC and GCNT3 mRNA molecules in the reinfected animals was indistinguishable from the drug-treated controls as well as from naïve controls (Figure 4).

Protein expression in the small intestine during infection was monitored using Western blot analysis (Figure 5). SPP1, a gene in the VDR/RXR activation pathway, was two fold higher in the reinfected animals $(N=4)$

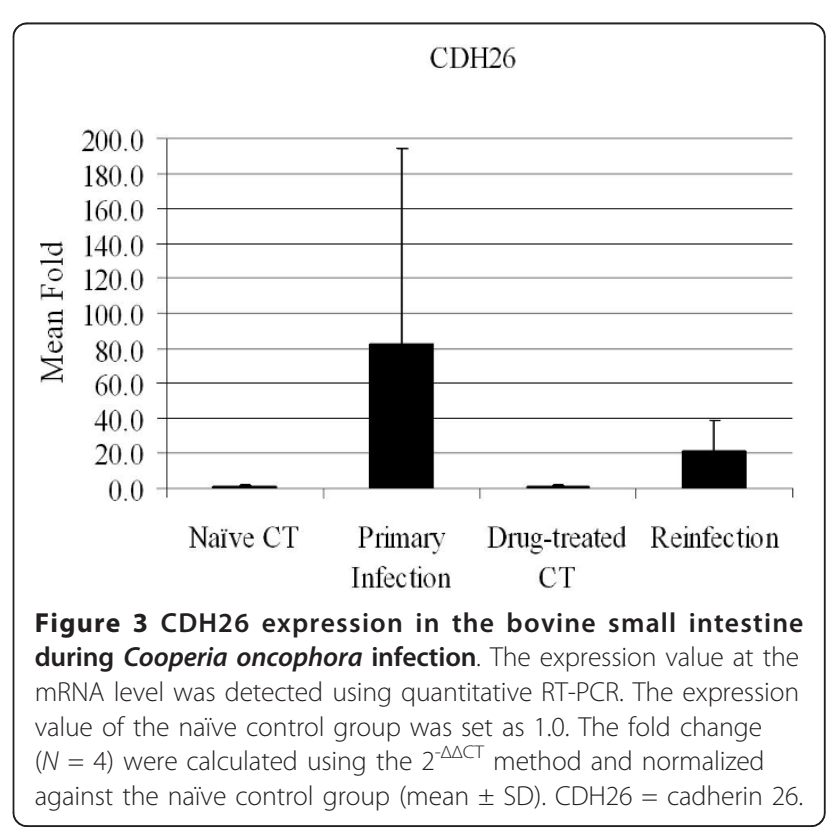




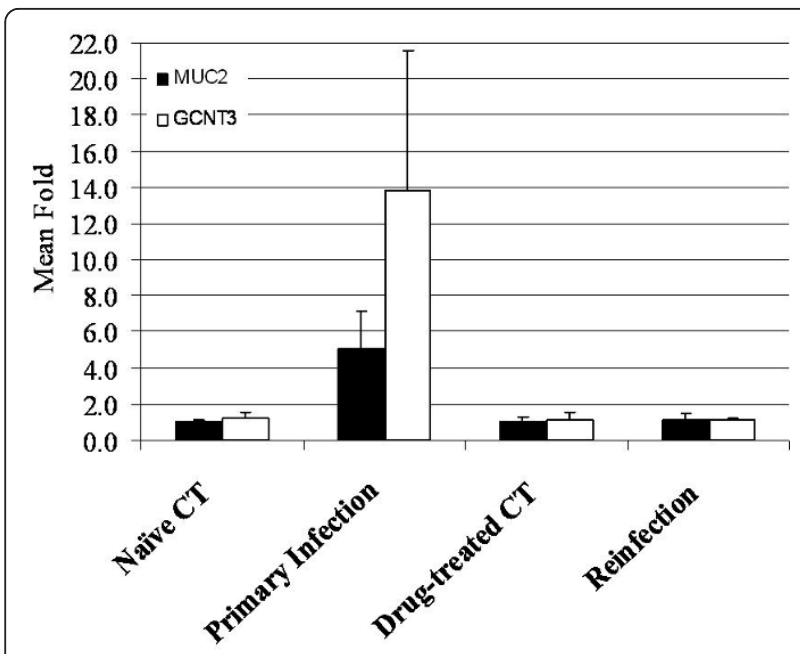

Figure 4 The expression of two genes in mucin biosynthesis in the bovine small intestine during Cooperia oncophora infection at $\mathbf{1 4} \mathbf{d p i}$. The expression value at the mRNA level was detected using quantitative RT-PCR. The expression value of the naive control group was set as 1.0. The fold change $(N=4)$ were calculated using the $2^{-\Delta \Delta C T}$ method and normalized against the naiive control group (mean $\pm \mathrm{SD}$ ). MUC2 = mucin 2, oligomeric mucus/gel-forming; GCNT3 = glucosaminyl (N-acetyl) transferase 3, mucin type.

compared to the drug-treated control $(N=4)$. This is consistent with mRNA results. SPP1 was also up-regulated in the primed animals ( 1.8 fold) compared to naïve controls. GCNT3 protein expression was elevated 3.5 fold during primary infection; and its elevated expression was maintained during reinfection but to a lesser extent (2.4 fold) compared to drug-treated controls (Figure 5).

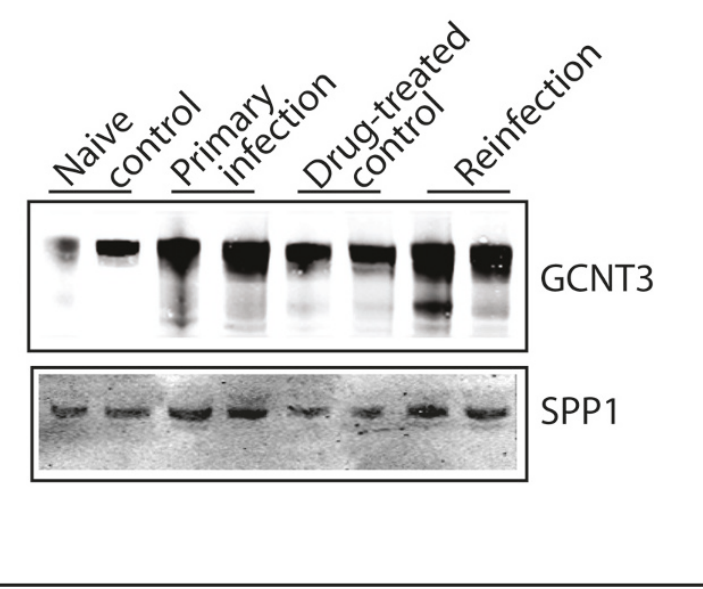

Figure 5 Western blot analysis of GCNT3 and SPP1 in the small intestine tissue (jejunum) during Cooperia oncophora infection at $\mathbf{1 4} \mathbf{d p i}$. The relative densities of the target bands were qualified using UNSCAN-IT from Silk Scientific. GCNT3 = glucosaminyl (N-acetyl) transferase 3, mucin type. SPP1= secreted phosphoprotein 1 (osteopontin).

\section{Discussion}

It has long been recognized that genetics plays an important role in the host's ability to resist gastrointestinal nematode infections in ruminants, even though the heritability of the resistance trait is relatively low to moderate in most cases. Different breeds and selection lines in ruminants differ greatly in their relative resistance [24-27]. Resistance is manifested in several distinct forms, including a reduced establishment of worms and retarded or arrested worm development as well as stunting and inhibition of egg production [28]. There have been numerous attempts to exploit the relative contribution of inherited components in susceptibility to GI nematodes in ruminants for its utilities in either applied breeding programs [29] or in understanding molecular mechanisms underlying the trait $[17,27]$. Acquired resistance, the ability of animals to become resistant after prior infection by pathogens, exposure to stress, or application of chemical inducers, is also well documented. In cattle, calves with previous exposure to a heavily contaminated pasture have a limited establishment of worms, compared to naïve calves that are exposed to the same pasture harboring over 380 times more worms [30]; the ability of calves to acquire resistance to $C$. oncophora appears to be independent of age. Several other studies also support the observation that priming with $C$. oncophora induces strong protective immunity, possibly due to its rapid elicitation of immunological reactions [16]. Understanding genetic and immunological mechanisms underlying the development of acquired resistance could have implications in vaccine design. While temporal responses of cytokine and biochemical pathways to $C$. oncophora infections, both natural and experimental, have been monitored recently $[7,31,32]$, molecular mechanisms underlying the development of acquired resistance have yet to be unraveled.

In this study, twenty three pathways were significantly impacted in the bovine small intestine during C. oncophora infection. Among these pathways, the VDR/ RXR activation pathway was strongly impacted only during reinfection, suggesting that this pathway may have played an important role in the development of acquired resistance. VDR partners with the retinoid $\times$ receptor, RXR, a member of the nuclear hormone receptor family, to form a heterodimer VDR-RXR. The heterodimer is then bound to Vitamin D3 as well as other co-activator proteins to mediate the transcriptional regulation of a number of genes. The activation plays a crucial role in the regulation and metabolism of calcium and phosphorus in the small intestine, kidney and bone as well as modulates the expression of genes in bile acid transport [33]. However, the function of VDR extends far beyond its classical boundary as a regulator of calcium homeostasis and bone metabolism. VDR is constitutively expressed in a variety of 
immune cells and plays an essential role in gastrointestinal inflammation and innate and adaptive immunity [34]. Mounting evidence suggests any disruption to vitamin D and/or its receptor could have serious consequences in a number of the key physiological processes, including immune function. VDR knock-out (KO) mice exhibit a pro-inflammatory bias and abolish the formation of NF$\kappa \mathrm{B}-\mathrm{VDR}$ complex. VDR KO mice have reduced CD4/ $\mathrm{CD} 8 \alpha \alpha$ intraepithelial lymphocyte populations in the gut and compromised $\mathrm{T}$ cell homing [35]. Therefore, VDR is an important contributor to host protection from bacterial infection and associated with colon tumor progress [36]. Vitamin D3 (calcitriol) treatment in humans induces a significant increase in circulating lymphocytes and the percentage of eosinophil vacuolization [37], a condition favoring a Th2 immune response, a hallmark of parasitic nematode infection. Our results show that increased expression of VDR and strong stimulation of the VDR/ RXR activation pathway during C. oncophora reinfection may contribute to intestinal repair. Many previously published reports demonstrate that vitamin D3 induces an increased expression of tight junction proteins such as claudins as well as E-cadherin; and its receptor, VDR, and is able to enhance the intercellular junctions [38]. VDR knockdown compromises tight junction functions. VDR plays important roles in maintaining the integrity of the intestinal mucosal barrier. While further evidence is needed to establish a solid link between the VDR pathway and the development of acquired resistance to C. oncophora infection in cattle, our findings nevertheless provide a novel direction for future research.

Nitric oxide (NO), one of the most versatile players in the immune system, is critical in host defense because of its cytotoxic and immunoregulatory properties $[39,40]$. The production of NO by nitric oxide synthases (NOS) in various cell types including macrophages is mainly controlled at the transcriptional level. Inducible nitric oxide synthase (NOS2) is widely expressed in many cell types. NOS2 is readily inducible by cytokines such as TNF $\alpha$, IL-1 $\beta$, and IFN- and/or microbial products, resulting in sufficient and sustained production of NO. NO in turn exerts numerous effector and immunoregulatory functions including killing of infectious pathogens and modulating cytokine production and Th cell development [41]. Reactive nitrogen intermediates (NO and its derivatives) are among the key effector molecules of parasite control in the livers of L. donovani-infected mice [42]. The host capable of controlling the infection of this intracellular parasite develops an effective $\mathrm{T}$ cell- dependent immune response mediated largely by Th1 cytokines, including IL-12 and IFN $-\gamma$. On the other hand, Th2 cells play a central role in mediating the protective immunity against parasitic nematode infections by releasing an array of cytokines, such as IL-4 and IL-13. These cytokines, via their receptors such as IL-4 receptor $\alpha$ (IL-4R $\alpha$ ), activates downstream signaling pathways. However, the induction of a Th2-type immune response leading to worm expulsion is complicated. A recent study suggests that neither the expression of this receptor on $\mathrm{CD} 4^{+} \mathrm{T}$ cells nor macrophages and neutrophils are required for protective immunity to Trichinella spiralis infection in mice [43].

Cooperia oncophora infection in cattle induces a Th2 immune response. However, dominant effector mechanisms controlling worm expulsion have yet to be identified. A significant increase in mucous IgA and IgG1 as well as an influx of eosinophils are evident during primary infection $[7,9]$. Th2 cytokines such as IL-4 and IL-13 are strongly up-regulated during a primary infection while TNF $\alpha$ and IFN- $\gamma$ remains largely unchanged. Results from this study demonstrated that NOS2 expression was up-regulated during reinfection (Figure 2). NOS2 was implicated in 5 of the 8 pathways induced during reinfection, including IL-12 signaling, IL-17 signaling, IL-6 signaling, and glucocorticoid receptor signaling pathways. The expression of IL-12 during C. oncophora infection in the bovine small intestine was not monitored in this study. Published studies suggest that ongoing Th2 responses are relatively stable and difficult to switch to a Th1 response [44]. IL-12 is a potent stimulus for Th1 responses and has previously shown to drive chronic $T$. muris infection in a normally resistant mouse strain $[45,46]$. Resistance can be generated either by a single infection event which exceeds the threshold or multiple sub-threshold infection episodes. The absolute level of parasites required to reach threshold varies between genetically distinct individuals. While resistance is generally associated with Th2 responses, it is possible that the development of acquired resistance to C. oncophora infection in cattle requires a delicate balance between the production of Th1 cytokines and Th2 cytokines.

The interaction of pathogen-associated molecular patterns such as carbohydrate moieties on parasites by host pattern recognition receptors (e.g. collectins and galectins) triggers a cascade of events, including activation of various immune cells and subsequent cytokine production and resultant recruitment of leukocytes to the site of infection in the bovine small intestine. A sustained elevation of inflammatory cytokines during priming induces NOS2 gene expression, leading to increased production of NO. These reactive nitrogen species and proteases released by infiltrates create a hostile environment for parasites, which impacts worm establishment and reproduction. Up-regulation of genes in extracellular matrix and tight junction as well as genes involved in mucin biosynthesis by infection may lead to enhanced tissue repair in the small intestine. These factors all 
contribute to the rapid development of acquired resistance to C. oncophora infection in cattle after priming by a high-dose primary infection.

In conclusion, we presented evidence that acquired resistance to C. oncophora infection in cattle can be rapidly developed following priming of the immune response. Multiple signaling pathways that were significantly impacted during reinfection were identified, distinct from those during a primary infection. The VDR/ RXR activation pathway may have contributed significantly to the development of acquired resistance via its potential roles in immune regulation and intestinal mucosal integrity maintenance. NOS2 expression was strongly induced; and several NOS2 associated pathways were significantly impacted during reinfection, suggesting they may play an important role in protective immunity. However, the development of acquired resistance is likely to be very complicated. The relative contribution of Th1 and Th2 immune responses to the resolution of C. oncophora infection in cattle needs to be experimentally defined.

\section{Additional material}

\section{Additional file 1: Genes significantly impacted during Cooperia oncophora infections in cattle. 308 unique sequences significantly regulated during Cooperia oncophora infections in cattle.}

Additional file 2: Pathways significantly impacted during Cooperia oncophora infections in cattle. 23 canonical pathways significantly impacted during Cooperia oncophora infections in cattle.

Additional file 3: Primers used in the experiment. Primers for 15 genes used in the experiment.

\section{Acknowledgements}

The authors thank Debbie Hebert and Joanne Wilson for their excellent technical assistance. Mention of trade names or commercial products in this publication is solely for the purpose of providing specific information and does not imply recommendation or endorsement by the U. S. Department of Agriculture.

\section{Authors' contributions}

RWL conceived the study, conducted the experiment, analyzed the data, and drafted the manuscript. CJL carried out Western blot analysis. LCG assisted in parasite infection experiments. All authors read and approved the final manuscript.

\section{Competing interests}

The authors declare that they have no competing interests.

Received: 5 October 2010 Accepted: 17 March 2011

Published: 17 March 2011

\section{References}

1. Lima WS: Seasonal infection pattern of gastrointestinal nematodes of beef cattle in Minas Gerais State-Brazil. Vet Parasitol 1998, 74:203-214.

2. Coop RL, Sykes AR, Angus KW: The pathogenicity of daily intakes of Cooperia oncophora larvae in growing calves. Vet Parasitol 1979, 5:261-269.

3. Armour J, Bairden K, Holmes PH, Parkins JJ, Ploeger H, Salman SK, McWilliam PN: Pathophysiological and parasitological studies on Cooperia oncophora infections in calves. Res Vet Sci 1987, 42:373-381.
4. Li RW, Li C, Elsasser TH, Liu G, Garrett WM, Gasbarre LC: Mucin biosynthesis in the bovine goblet cell induced by Cooperia oncophora infection. Vet Parasitol 2009, 165:281-289.

5. Gasbarre LC, Leighton EA, Sonstegard T: Role of the bovine immune system and genome in resistance to gastrointestinal nematodes. Vet Parasitol 2001, 98:51-64.

6. Kanobana K, Ploeger HW, Vervelde L: Immune expulsion of the trichostrongylid Cooperia oncophora is associated with increased eosinophilia and mucosal IgA. Int J Parasitol 2002, 32:1389-1398.

7. Li RW, Gasbarre LC: A temporal shift in regulatory networks and pathways in the bovine small intestine during Cooperia oncophora infection. Int J Parasitol 2009, 39:813-824.

8. Kanobana K, Koets A, Kooyman FN, Bakker N, Ploeger HW, Vervelde L: B cells and antibody response in calves primary-infected or re-infected with Cooperia oncophora: influence of priming dose and host responder types. Int J Parasitol 2003, 33:1487-1502.

9. Kanobana K, Vervelde L, Van Der Veer M, Eysker M, Ploeger HW: Characterization of host responder types after a single Cooperia oncophora infection: kinetics of the systemic immune response. Parasite Immunol 2001, 23:641-653.

10. Nieuwland MG, Ploeger HW, Kloosterman A, Parmentier HK: Systemic antibody responses of calves to low molecular weight Cooperia oncophora antigens. Vet Parasitol 1995, 59:231-239.

11. Dobson RJ, Waller PJ, Donald AD: Population dynamics of Trichostrongylus colubriformis in sheep: the effect of host age on the establishment of infective larvae. Int J Parasitol 1990, 20:353-357.

12. Gasbarre LC, Leighton EA, Davies CJ: Influence of host genetics upon antibody responses against gastrointestinal nematode infections in cattle. Vet Parasitol 1993, 46:81-91.

13. Li RW, Hou Y, Li C, Gasbarre LC: Localized complement activation in the development of protective immunity against Ostertagia ostertagi infections in cattle. Vet Parasitol 2010, 175:247-256.

14. Kanobana K, Ploeger HW, Eysker M, Vervelde L: Individual variation and effect of priming dose level on establishment, growth and fecundity of Cooperia oncophora in re-infected calves. Parasitology 2004, 128:99-109.

15. Dorny $\mathrm{P}$, Claerebout $E$, Vercruysse J, Hilderson H, Huntley JF: The influence of a Cooperia oncophora priming on a concurrent challenge with Ostertagia ostertagi and C. oncophora in calves. Vet Parasitol 1997 70:143-151.

16. Eysker M, Boersema JH, Kooyman FN, Ploeger HW: Resilience of second year grazing cattle to parasitic gastroenteritis following negligible to moderate exposure to gastrointestinal nematode infections in their first year. Vet Parasitol 2000, 89:37-50.

17. Li RW, Meyer MJ, Van Tassell CP, Sonstegard TS, Connor EE, Van Amburgh ME, Boisclair YR, Capuco AV: Identification of estrogenresponsive genes in the parenchyma and fat pad of the bovine mammary gland by microarray analysis. Physiol Genomics 2006, 27:42-53.

18. Livak KJ, Schmittgen TD: Analysis of relative gene expression data using real-time quantitative PCR and the $2^{\Delta \Delta C T}$ Method. Methods 2001, 25:402-408.

19. Irizarry RA, Hobbs B, Collin F, Beazer-Barclay YD, Antonellis KJ, Scherf U, Speed TP: Exploration, normalization, and summaries of high density oligonucleotide array probe level data. Biostatistics 2003, 4:249-264.

20. Bolstad BM, Irizarry RA, Astrand M, Speed TP: A comparison of normalization methods for high density oligonucleotide array data based on variance and bias. Bioinformatics 2003, 19:185-193.

21. MultiExperiment Viewer. [http://www.tm4.org/mev]

22. Guo L, Lobenhofer EK, Wang C, Shippy R, Harris SC, Zhang L, Mei N, Chen T, Herman D, Goodsaid FM, Hurban P, Phillips KL, Xu J, Deng X Sun YA, Tong W, Dragan YP, Shi L: Rat toxicogenomic study reveals analytical consistency across microarray platforms. Nat Biotechnol 2006, 24:1162-1169.

23. Li RW, Capuco AV: Canonical pathways and networks regulated by estrogen in the bovine mammary gland. Funct Integr Genomics 2008, 8:55-68

24. Burke JM, Miller JE: Relative resistance of Dorper crossbred ewes to gastrointestinal nematode infection compared with St. Croix and Katahdin ewes in the southeastern United States. Vet Parasitol 2009 109:265-275

25. Golding N, Small RW: The relative resistance to gastrointestinal nematode infection of three British sheep breeds. Res Vet Sci 2009, 87:263-264. 
26. Gonzalez JF, Hernandez A, Molina JM, Fernandez A, Raadsma HW, Meeusen EN, Piedrafita D: Comparative experimental Haemonchus contortus infection of two sheep breeds native to the Canary Islands. Vet Parasitol 2008, 153:374-378.

27. Li RW, Sonstegard TS, Van Tassell CP, Gasbarre LC: Local inflammation as a possible mechanism of resistance to gastrointestinal nematodes in Angus heifers. Vet Parasitol 2007, 145:100-107.

28. Michel JF: Some aspects of resistance to animal and human helminths. Acquired resistance and its effect on populations of Ostertagia ostertagi. Proc R Soc Med 1967, 60:167-168.

29. Coppieters W, Mes TH, Druet T, Farnir F, Tamma N, Schrooten C, Cornelissen AW, Georges M, Ploeger HW: Mapping QTL influencing gastrointestinal nematode burden in Dutch Holstein-Friesian dairy cattle. BMC Genomics 2009, 10:96.

30. Smith HJ, Archibald RM: The effects of age and previous infection on the development of gastrointestinal parasitism in cattle. Can J Comp Med 1968, 32:511-517.

31. Bricarello PA, Zaros LG, Coutinho LL, Rocha RA, Silva MB, Kooyman FN, de Vries E, Yatsuda AP, Amarantem AF: Immunological responses and cytokine gene expression analysis to Cooperia punctata infections in resistant and susceptible Nelore cattle. Vet Parasitol 2008, 155:95-103.

32. Li RW, Gasbarre LC: Gene expression in the bovine gastrointestinal tract during nematode infection. In Veterinary Parasitology. Edited by: LaMann G. Nova Biomedical Press, New York; 2010:157-178.

33. Ogura M, Nishida S, Ishizawa M, Sakurai K, Shimizu M, Matsuo S, Amano S, Uno S, Makishima M: Vitamin D3 modulates the expression of bile acid regulatory genes and represses inflammation in bile duct-ligated mice. J Pharmacol Exp Ther 2009, 328:564-570.

34. Froicu M, Zhu Y, Cantorna MT: Vitamin D receptor is required to control gastrointestinal immunity in IL-10 knockout mice. Immunology 2006, 117:310-318.

35. Yu S, Bruce D, Froicu M, Weaver V, Cantorna MT: Failure of T cell homing, reduced CD4/CD8alphaalpha intraepithelial lymphocytes, and inflammation in the gut of vitamin D receptor KO mice. Proc Natl Acad Sci USA 2008, 105:20834-20839.

36. Wada K, Tanaka H, Maeda K, Inoue T, Noda E, Amano R, Kubo N, Muguruma K, Yamada N, Yashiro M, Sawada T, Nakata B, Ohira M, Hirakawa K: Vitamin D receptor expression is associated with colon cancer in ulcerative colitis. Oncol Rep 2009, 22:1021-1025.

37. Snyman JR, de Sommers K, Steinmann MA, Lizamore DJ: Effects of calcitriol on eosinophil activity and antibody responses in patients with schistosomiasis. Eur J Clin Pharmacol 1997, 52:277-280.

38. Kong J, Zhang Z, Musch MW, Ning G, Sun J, Hart J, Bissonnette M, Li YC: Novel role of the vitamin $D$ receptor in maintaining the integrity of the intestinal mucosal barrier. Am J Physiol Gastrointest Liver Physiol 2008, 294 : G208-G216.

39. Garcia X, Stein F: Nitric oxide. Semin Pediatr Infect Dis 2006, 17:55-57.

40. Murray HW, Nathan CF: Macrophage microbicidal mechanisms in vivo: reactive nitrogen versus oxygen intermediates in the killing of intracellular visceral Leishmania donovani. J Exp Med 1999, 189:741-746.

41. Nathan C, Shiloh MU: Reactive oxygen and nitrogen intermediates in the relationship between mammalian hosts and microbial pathogens. Proc Natl Acad Sci USA 2000, 97:8841-8848.

42. Bogdan C: Nitric oxide and the immune response. Nat Immunol 2001, 2:907-916.

43. Michels CE, Scales HE, Saunders KA, McGowan S, Brombracher F, Alexander J, Lawrence CE: Neither interleukin-4 receptor alpha expression on CD4+ T cells, or macrophages and neutrophils is required for protective immunity to Trichinella spiralis. Immunology 2009, 128: e385-e394.

44. Perez VL, Lederer JA, Lichtman AH, Abbas AK: Stability of Th1 and Th2 populations. Int Immunol 1995, 7:869-875.

45. Bancroft AJ, Else KJ, Humphreys NE, Grencis RK: The effect of challenge and trickle Trichuris muris infections on the polarisation of the immune response. Int J Parasitol 2001, 31:1627-1637.

46. Bancroft AJ, Else KJ, Sypek JP, Grencis RK: Interleukin-12 promotes a chronic intestinal nematode infection. Eur J Immunol 1997, 27:866-870.

doi:10.1186/1297-9716-42-48

Cite this article as: $L i$ et al.: The vitamin $D$ receptor and inducible nitric oxide synthase associated pathways in acquired resistance to Cooperia oncophora infection in cattle. Veterinary Research 2011 42:48.

\section{Submit your next manuscript to BioMed Central and take full advantage of:}

- Convenient online submission

- Thorough peer review

- No space constraints or color figure charges

- Immediate publication on acceptance

- Inclusion in PubMed, CAS, Scopus and Google Scholar

- Research which is freely available for redistribution

Submit your manuscript at www.biomedcentral.com/submit
C Biomed Central 